\title{
Aspects of attention that affect compliance and general behavior in disruptive and typical children
}

Holly Ann Filcheck

West Virginia University

Follow this and additional works at: https://researchrepository.wvu.edu/etd

\section{Recommended Citation}

Filcheck, Holly Ann, "Aspects of attention that affect compliance and general behavior in disruptive and typical children" (2000). Graduate Theses, Dissertations, and Problem Reports. 867.

https://researchrepository.wvu.edu/etd/867

This Thesis is protected by copyright and/or related rights. It has been brought to you by the The Research Repository @ WVU with permission from the rights-holder(s). You are free to use this Thesis in any way that is permitted by the copyright and related rights legislation that applies to your use. For other uses you must obtain permission from the rights-holder(s) directly, unless additional rights are indicated by a Creative Commons license in the record and/ or on the work itself. This Thesis has been accepted for inclusion in WVU Graduate Theses, Dissertations, and Problem Reports collection by an authorized administrator of The Research Repository @ WVU. For more information, please contact researchrepository@mail.wvu.edu. 


\title{
Aspects of Attention that Affect Compliance and General Behavior in Disruptive and Typical Children
}

\author{
Holly A. Filcheck \\ Thesis submitted to the \\ College of Arts and Sciences \\ at West Virginia University \\ in partial fulfillment of the requirements \\ for the degree of \\ Master of Arts \\ in \\ Child Clinical Psychology \\ Cheryl B. McNeil, Ph.D., Chair \\ Christina Adams, Ph.D. \\ Stanley Cohen, Ph.D. \\ Department of Psychology \\ Morgantown, West Virginia \\ 2000
}

Keywords: Compliance, Disruptive Children, General Behavior, Head Start, Attention 


\section{ABSTRACT \\ Aspects of Attention that Affect Compliance and General Behavior in Disruptive and Typical Children}

\section{Holly A. Filcheck}

Currently, there is some controversy concerning whether praise affects compliance and behavior other than compliance (i.e., general behavior) in children with disruptive behaviors. It is unclear whether it is praise or other aspects of general attention, such as descriptions and enthusiasm, that influences children's behavior. The current study examined the effects of enthusiastic praise, non-enthusiastic praise, and non-enthusiastic description on child compliance (measured by the Compliance Test) and general behavior (measured by the Marble-in-the-Hole Game) in 15 children with disruptive behavior problems and 15 typical children. Results indicated that the participants had significantly higher rates of compliance in the non-enthusiastic description condition than in the enthusiastic praise condition across groups. In addition, participants had significantly higher rates of general behavior in the enthusiastic praise condition than in the nonenthusiastic description condition across groups. Results are discussed with regard to the effectiveness of the different types of attention used in different situations. 


\section{Acknowledgments}

This project could not have been completed without the unconditional support and guidance of Dr. Cheryl McNeil, committee chair, whose positive supervisory style has made this a wonderful experience. I would like to express my deepest gratitude and admiration to her. I also would like to sincerely thank my committee members, Dr. Christina Adams and Dr. Stan Cohen for all of their thoughtful suggestions and assistance.

In addition, I want to extend my appreciation to Amy Herschell who has provided me with useful and constructive feedback concerning this project. She has been supportive and extremely helpful throughout the process of completing this milestone. Successful completion of this project also depended on my remarkable research assistants, Traci Berry and Christine Estep, who spent many long hours helping me with this project.

I also want to thank the administrators and teachers of the local head start classrooms in which I collected my data. Without their assistance, this project would not have been possible.

I am sincerely grateful to Ronald Martin for his unconditional assistance and support throughout the completion of this project. Finally, I wish to thank my parents, Patricia and William Filcheck, whose positive support and love has made the accomplishment of my goals seem like an easy task. 
Title Page

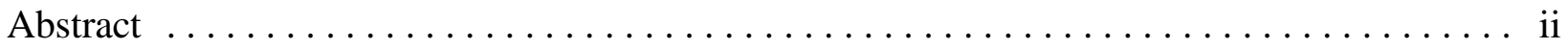

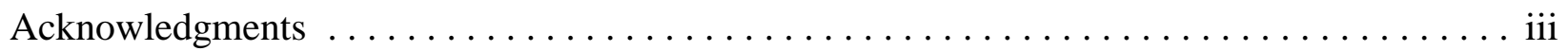

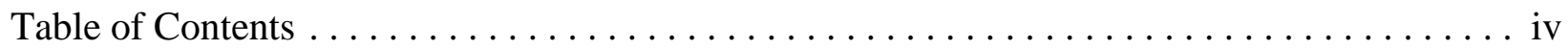

List of Tables $\ldots \ldots \ldots \ldots \ldots \ldots \ldots \ldots \ldots \ldots \ldots \ldots \ldots \ldots \ldots \ldots \ldots \ldots \ldots \ldots$

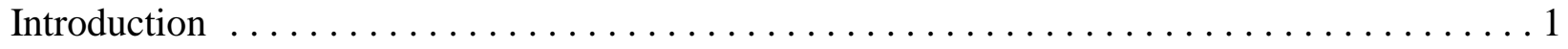

Changing Behavior Using Praising and Ignoring $\ldots \ldots \ldots \ldots \ldots \ldots \ldots \ldots \ldots \ldots \ldots$

Praising Compliance in Typical Children $\ldots \ldots \ldots \ldots \ldots \ldots \ldots \ldots \ldots \ldots \ldots \ldots \ldots \ldots \ldots \ldots \ldots$

Praising General Behavior in Typical Children $\ldots \ldots \ldots \ldots \ldots \ldots \ldots \ldots$

Praising Compliance in Children with Disruptive Behaviors $\ldots \ldots \ldots \ldots \ldots \ldots$

Praising Compliance Combined with Time out in Children with Disruptive Behaviors .8

Using Attention and Time out for General Behavior in Children with Disruptive

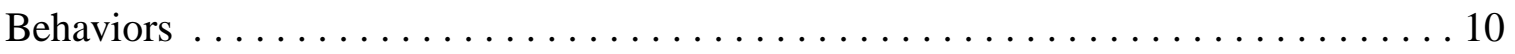

The Effects of Praise on Compliance in the Classroom . . . . . . . . . . . . 10

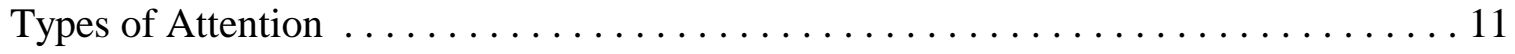

The Effects of Enthusiasm on Compliance and General Behavior $\ldots \ldots \ldots \ldots \ldots 11$

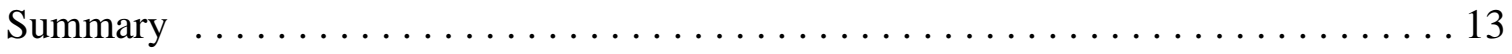

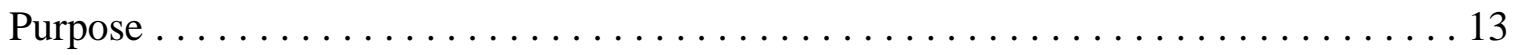

Hypotheses . . . . . . . . . . . . . . . . . . . . . 14

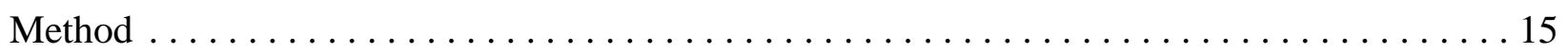

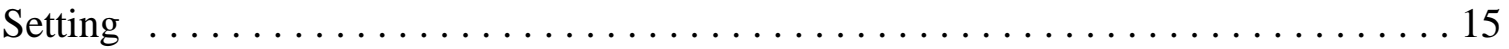




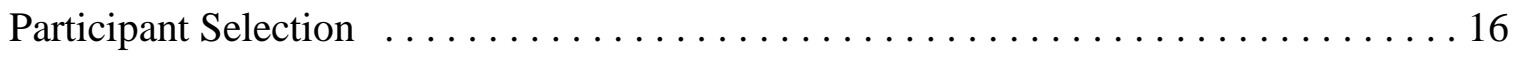

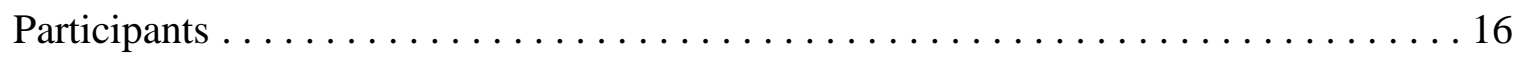

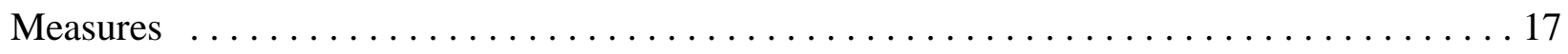

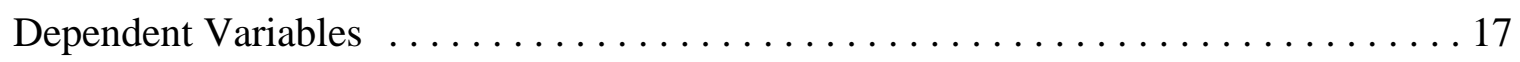

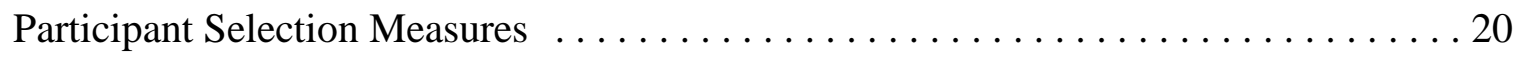

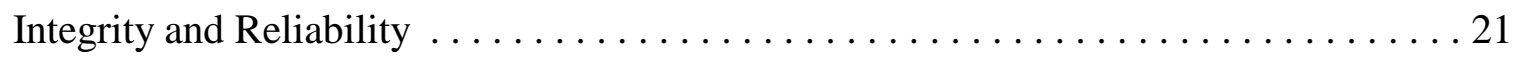

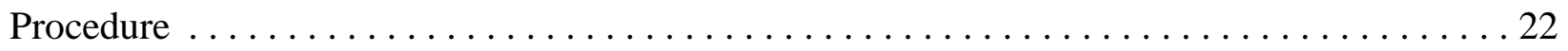

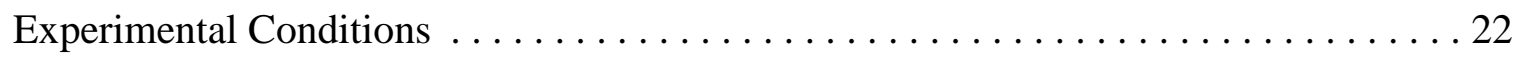

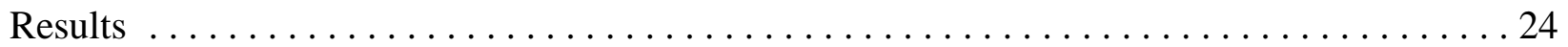

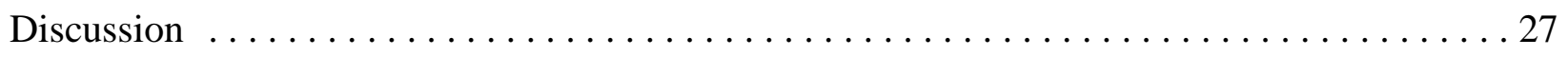

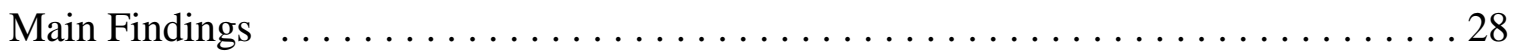

Methodological Limitation and Suggestions for Future Directions . . . . . . . . . 35

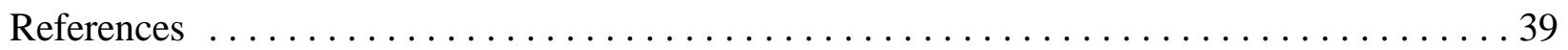

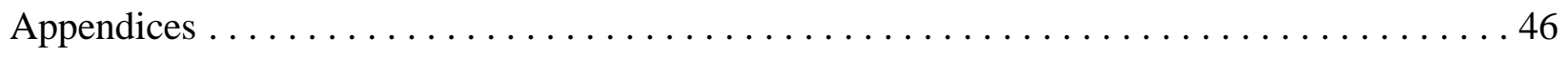

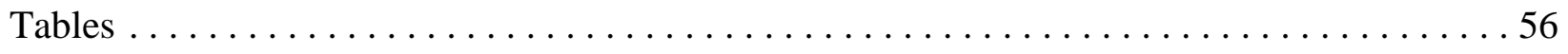




\section{List of Tables}

$\underline{\text { Tables }}$

Table 1. Means and Standard Deviations for the Compliance Test . . . . . . . . . . 56

Table 2. Missing Data Points in the Marble-in-the-Hole Game . . . . . . . . . . . . . . 57

Table 3. Means and Standard Deviations for the Marble-in-the-Hole Game . . . . . . . . 58 
Aspects of Attention that Affect Compliance and General Behavior in Disruptive and Typical Children

Several studies have been conducted to examine the effects of praise on child compliance (e.g., Bernhardt \& Forehand, 1975; Eisenstadt, Eyberg, McNeil, Newcomb, \& Funderburk 1993; Pfiffner \& O’Leary, 1987; Pfiffner, Rosén, \& O’Leary, 1985; Roberts, 1985; Roberts, Hatzenbuehler, \& Bean, 1981). However, there are currently no studies to suggest whether it is praise or other aspects of general attention, such as descriptions and enthusiasm (e.g., looking at a child, talking to a child, showing excitement for a child's activities) (refer to Appendix A) that influences children's behavior. Because this distinction has been overlooked in the literature, it is unclear if a descriptive statement is equivalent to praise in influencing behavior. It is also unclear whether the level of enthusiasm would influence child behavior. For example, when a child's compliance with a request to clean up toys is followed by praise combined with enthusiasm ("Wow, you did a great job cleaning up the toys!"), rather than just praise alone, will the cleaning behavior increase, decrease, or remain the same? Similarly, how will compliance behavior be affected by a non-enthusiastic description of the child's behavior ("You cleaned up the toys.")? The current study examined the effects of enthusiastic praise, non-enthusiastic praise, and non-enthusiastic description on child compliance (i.e., following an instruction) and general behavior (i.e., any behavior other than compliance) in children with disruptive behavior problems and typical children (see Appendix A for definitions). The results of this study have implications for parent and teacher training programs that focus on the selective use of attention to modify disruptive behavior.

This paper is organized in the following manner. First, general issues surrounding 
praising compliance and ignoring noncompliance are discussed. Second, the effects of praise on compliance and general behavior in typical children and in children exhibiting disruptive behaviors are presented. Third, the practice of using praise and attention in the classroom is reviewed. Fourth, the role of enthusiasm on compliance and general behavior is theorized. Finally, the purpose and hypotheses of the study are presented.

Changing Behavior Using Praising and Ignoring

Compliance is considered a critical behavior to target for change in children with disruptive behavior problems. Because of research like that of Loeber and Schmaling (1985) who suggested that noncompliance is the core concern with children exhibiting disruptive behaviors, parent training programs often focus on noncompliance. These authors have shown that treating noncompliance may promote improvement of many other misbehaviors without direct intervention. Behavioral parent training programs usually focus a great deal of attention on noncompliance, but address modification of general behavior as well. For example, Parent-Child Interaction Therapy (PCIT) is a parent training program that teaches parents to praise compliance and to use a mild punishment (i.e., time out) for noncompliance with children exhibiting disruptive behaviors (Hembree-Kigin \& McNeil, 1995). However, PCIT also focuses on targeting such general behavior as sharing, staying seated, being polite, and playing gently.

Praising child compliance is a skill that is commonly used by parents, teachers, and clinicians. The premise behind praise is that social acceptance is reinforcing, causing specific behaviors to increase. It has been found that typical children receive more praise by their mothers than children with conduct problems, but, interestingly, children with conduct problems receive more praise by their fathers than typical children (Robinson \& Eyberg, 1981). The 
findings from Robinson and Eyberg's (1981) study indicated that in a 10-minute period, mothers of typical children gave 5.20 praises and mothers of children with conduct problems gave 2.30 praises. In contrast, fathers of typical children gave 2.81 praises and fathers of children with conduct problems gave 5.50 praises. Thus, the amount of praise received by the child depends on whether that child exhibits disruptive or typical behavior, as well as the caregiver with which the child is interacting. The authors suggest that these results may have been obtained because the children with conduct problems were mostly boys whereas the typical children were mostly girls.

Praise is used frequently as a method of positive reinforcement in parent training programs for managing disruptive behaviors. For example, Hembree-Kigin and McNeil (1995) teach parents to use labeled praise to increase appropriate child behavior. A labeled praise is defined as any parent verbalization that tells the child exactly what the parent liked about his or her behavior (Appendix A) (Bernhardt \& Forehand, 1975; Eyberg \& Robinson, 1983; HembreeKigin \& McNeil, 1995). Webster-Stratton (1996) teaches the use of praise in her videotape modeling program for families of children with oppositional defiant disorder or conduct disorder. Forehand and McMahon (1981), Barkley (1987), and Eyberg (1988) also teach the concept of praise in their programs. Therefore, it is widely believed that praising a behavior will cause it to increase, regardless of whether a child displays typical or disruptive behavior.

Along with praising child compliance, parent training programs usually teach parents to actively ignore minor disruptive behaviors. Parents also are taught to provide consistent consequences (e.g., time out) for child noncompliance. Active ignoring is taught because it is thought that removing attention (i.e., reinforcement) for negative attention-seeking behavior will 
result in a decrease in these behaviors (see Appendix A) (Hembree-Kigin \& McNeil, 1995).

Davies, McMahon, Flessati, and Tiedemann (1984) examined whether ignoring alone, ignoring including a rationale of the procedure, ignoring including a rationale and modeling of the procedure, or no ignoring were effective in increasing child compliance and decreasing inappropriate behavior in typical children. They found that compliance increased when children were ignored with a rationale or with a rationale and modeling, and that there was no difference in compliance levels of the children who were just ignored, or not ignored for noncompliance (Davies et al., 1984). This study suggests that ignoring a typical child for noncompliance will not affect compliance unless it is paired with a rationale. Forehand, Roberts, Doleys, Hobbs, and Resick (1976) also examined the effect of ignoring noncompliant behavior on compliance levels in typical children. Mothers were trained to do one of the following: ignore, provide negative attention, isolate the child, or provide a combination of all in response to child noncompliance (Forehand et al., 1976). Surprisingly, it was found that each of the conditions was effective in increasing compliant behavior in typical children (Forehand et al.). This study implies that, for typical children, negative attention (i.e., criticism) will decrease noncompliant behavior. It is unclear whether similar results would be obtained with children exhibiting disruptive behaviors. Nevertheless, it has been shown by Forehand et al. that ignoring noncompliant behavior will cause that behavior to decrease. Thus, the function of noncompliant behavior may be attention since removal of attention decreases noncompliant behavior.

Parent training programs have been shown to be effective in using praising and ignoring to decrease disruptive and noncompliant behavior (Eyberg \& Robinson, 1982). For example, Parent-Child Interaction Therapy (PCIT) is a parent training program that is based on the Hanf 
two-stage model (Hanf, 1969). The first stage in this model is called the child-directed interaction because the child leads the interaction, and the second stage is called the parentdirected interaction because the parent leads the interaction. Despite the overall effectiveness of Hanf model programs, only small increases in compliance are found after the child leads the interaction. However, dramatic increases in compliance are found after the parent leads the interaction, which includes a mild punishment procedure (time out) (Eisenstadt et al., 1993). Thus, it is important to determine the manner in which these parent training programs can become more effective in the child-directed interaction phase of treatment.

There is some evidence to suggest that praise is reinforcing for children with disruptive behavior problems for general behaviors (e.g., using an inside voice), but, praise alone does not affect their level of compliance (Roberts, 1985). Many researchers have found that compliance levels increase in children with disruptive behavior problems only when praise is combined with mild punishment procedures such as time out (Budd, Green, \& Baer, 1976; Eisenstadt et al., 1993; Roberts, Hatzenbuehler, \& Bean, 1981).

\section{Praising Compliance in Typical Children}

In general, it has been shown that typical children are compliant approximately 51-62\% of the time (Eyberg \& Robinson, 1983; Forehand, Gardner, \& Roberts, 1978). With regard to the effects of praise on compliance, children with typical behavior have been shown to increase their level of compliance when they are praised (Parpal \& Maccoby, 1985). Parpal and Maccoby conducted a study in which mothers were instructed not to interact with their typical children while they played, to play with their children like they normally would, or to play positively with their children using skills such as imitations and descriptions. In the positive play condition, 
mothers were not specifically taught to use praise, but praise was scored as a positive skill in the final analysis of the data. After this initial period, the Compliance Test was administered, and it was concluded that compliance levels increased for those children whose mothers were positively responsive to their play, and for those children whose mothers were noninteractive in their play. Therefore, according to Parpal and Maccoby general positive attention, including praise, will increase compliance in typical children.

\section{Praising General Behavior in Typical Children}

Praising general behavior (behaviors other than compliance) also has been found to increase typical children's behavior (Bernhardt \& Forehand, 1975). Bernhardt and Forehand used a procedure in which a child dropped marbles in either a green or red hole for a baseline period. From this baseline, a least-preferred hole was determined. After the determination, the child was praised for dropping the marbles in the least-preferred hole (i.e., the Marble-in-theHole Game) to determine the effects of labeled praise on typical children of different social classes. It was found that, irrespective of class, labeled praise was effective in changing children's general behavior. Thus, it appears that praise increases compliance levels and general behavior in typical children.

\section{$\underline{\text { Praising Compliance in Children with Disruptive Behaviors }}$}

Currently, there is no literature to suggest that praise affects compliance in children with disruptive behavior. Most research maintains that praising does not influence the compliance of these children (Roberts, 1985). Roberts conducted three projects to determine whether praising child compliance resulted in increased compliance or whether therapists recommended the practice of praising compliance simply as a matter of routine. In his first study, Roberts used the 
Compliance Test and the Marble-in-the-Hole Game to determine if parental praise for compliance, as well as warnings and time outs for noncompliance, affected disruptive children's behavior. He found that children were reinforced by praise with regard to general behavior (i.e., Marble-in-the-Hole Game). In project 2, the Compliance Test was used again, and the mothers of children with disruptive behaviors were instructed either to praise child compliance or to ignore child noncompliance, and to use warnings, time outs, and child-centered play. This project was done to determine if praise was an appetitive reinforcer. In other words, if it is praise that causes an increase in compliance, "then withholding praise should produce an extinction effect" (Roberts, p. 618). It was found that compliance levels were high regardless of the use of praise. Thus, praise was not concluded to be an appetitive reinforcer, and was not considered to be the reason that children complied to their mothers' instructions. Project 3 included a single subject (the author's son) who completed the Compliance Test in which no praise was given after compliance. After 480 trials, the participant's compliance rate was $81.5 \%$. Therefore, according to Roberts (1985), the absence of extinction after 480 trials demonstrates that parental praise does not reinforce child compliance. In sum, Roberts' projects suggest that children with disruptive behavior problems are responsive to praise concerning general behavior, but are unlikely to increase their compliance when they are praised. Praise may just be taught by clinicians and used by parents and teachers out of habit, not out of necessity.

However, there are a few concerns with Roberts' (1985) research. First, he assumed that the Marble-in-the-Hole Game was a test of compliance and, therefore, comparable to the Compliance Test. However, the Marble-in-the-Hole Game actually examines if a child will continue engaging in a behavior if praised for that behavior. This game does not involve 
commands issued by the examiner. Instead, the examiner simply praises the child for dropping a marble in a predetermined, non-preferred hole. Essentially, the Marble-in-the-Hole Game is measuring the effects of praise on general behavior, not compliance levels. Second, in projects 2 and 3, Roberts found that children with disruptive behaviors maintained their compliance levels in spite of the lack of praise. It follows that the function of compliance/noncompliance in children with disruptive behavior problems is not to gain social acceptance (i.e., praise). Instead, it is possible that compliance/noncompliance may serve the function of control or task avoidance. Yet, some research contradicts these assumptions. For example, Reimers et al. (1993) examined the function of noncompliant behavior in children with disruptive behavior problems. Three conditions were present in this study: a free play condition, an attention condition in which attention was given for noncompliance, and an escape condition in which prompts and physical guidance were used and noncompliance to the prompts resulted in a brief escape period for the child. Praise was used for compliance. For over half of the children with disruptive behavior problems, noncompliance was found to be a function of both parental attention and escape (Reimers et al.).

\section{$\underline{\text { Praising Compliance Combined with Time out in Children with Disruptive Behaviors }}$}

Some studies suggest that praise does affect compliance in children with disruptive behavior problems when praise is combined with a mild punishment. In other words, praise alone is not enough to affect subsequent child compliance; time out also must be used. In a study by Eisenstadt et al. (1993), participants, which consisted of children with disruptive behavior problems and their parents, were divided into two groups: those who were taught child-directed interaction (CDI) skills first, and those who were taught parent-directed interaction (PDI) skills 
first. CDI skills were considered to "strengthen a positive and mutually rewarding relationship between the parent and child" (Eisenstadt et al., p. 43) and included: praising appropriate behavior, ignoring inappropriate behavior, allowing the child to lead the play, describing, imitating, reflecting, as well as, avoiding commands, criticisms and leading questions. PDI skills included: time out, clearly and positively stated direct commands, and consistent consequences. At the half way point in the study, those participants in the CDI group had only a small increase in compliance, and those in the PDI group had dramatic increases in compliance. The compliance levels of the children in the PDI group went from outside normal limits to within normal limits. These findings suggest that praise alone does not have a great impact on child compliance, whereas mild punishment procedures strongly affect child compliance. In other words, discipline skills that parents are taught to decrease problematic behavior improved child compliance and decreased disruptive behaviors (Eisenstadt et al.).

Budd et al. (1976) also found that attention does not increase desired behavior in the absence of time out with children with behavior problems. These authors trained a mother to withhold social attention for her child's mildly inappropriate behavior (e.g., playing roughly with toys) and to use time out for her child's more extreme disruptive behavior (e.g., noncompliance). Using a procedure similar to the Compliance Test, these authors found that reducing the amount of social attention given to the child when the child behaved undesirably caused the child to decrease her inappropriate behaviors, but did not result in complete improvement (Budd et al.). Complete remediation of undesirable behavior was achieved only after implementation of time out (Budd et al.). Roberts et al. (1981) found results similar to Budd et al. using the Compliance Test to determine if attention alone, consisting only of praise, could increase compliance levels. 
Mothers were either taught to praise compliance, use time out for noncompliance, or combine these two strategies (Roberts et al.). It was found that attention did not have a substantial effect on increasing compliance levels without the use of time out (Roberts et al.). In fact, "the absence of a time out contingency was associated with decreasing compliance ratios" (Roberts et al., p. 98). Thus, several studies conclude that increasing compliance in children with disruptive behaviors will only be successful when used in conjunction with a mild punishment (e.g., time out).

Using Attention and Time out for General Behavior in Children with Disruptive Behaviors

Wahler (1969) also was concerned with the effects of differential attention and the use of time out on general behavior in children with disruptive behavior problems. In his study, parentchild interactions were observed to determine compliance levels and social attention given to child behaviors. Parents were then trained in the use of differential attention and time out. Increases in general behavior were determined using the Marble-in-the-Hole Game. Wahler concluded that the use of differential attention and time out produced increases in appropriate behavior, and that these combined efforts, in turn, produced increases in general behavior. These results suggest that, without the use of time out, differential attention is not enough to increase general behavior in children with disruptive behaviors.

The Effects of Praise on Compliance in the Classroom

Praise also has been found to be ineffective in increasing compliance in the classroom with children with disruptive behavior problems (Pfiffner \& O’Leary, 1987; Pfiffner, et al., 1985). Pfiffner et al. trained teachers to use positive consequences (e.g., praise), negative consequences, (e.g., verbal or physical signs of disapproval), and enhanced positive 
consequences, (e.g., new and special rewards in the classroom). On different days, the teachers used positive consequences alone, positive and negative consequences, or enhanced positive consequences alone to determine their effects on off-task behavior (Pfiffner et al.). It was found that regular positive consequences alone, including praise, did not maintain on-task behavior with children with disruptive behavior problems (Pfiffner et al.). Thus, it is confirmed that "behavior problem children cannot be successfully managed in an all-positive environment...when praise is the primary form of positive feedback" (Pfiffner et al., p. 260). In a similar study, Pfiffner and O'Leary (1987) found that enhanced positive consequences only had a stable effect on on-task behavior when negative consequences were used. When negative consequences were added to an enhanced positive approach in the classroom, on-task behavior increased, and when it was withdrawn, on-task behavior immediately decreased (Pfiffner \& O'Leary). Thus, it may be that praise alone is not enough to increase appropriate behaviors in children with behavior problems in the classroom, and elsewhere.

\section{$\underline{\text { Types of Attention }}$}

There may be types of attention other than praise that affect child compliance. For example, it has been found that responsive play, in which mothers used descriptions, imitations, and praise, leads to child compliance significantly more often than when mothers did not use these skills (Parpal \& Maccoby, 1985). According to Wahler and Bellamy (1997), responsive parenting produced synchrony and reciprocity. Thus, children reciprocated the skills that they learned from their parents. From this, it may be argued that praise for compliance may not be the key to decreasing disruptive behaviors in children (Wahler \& Bellamy). Therefore, it could be that any type of social and responsive attention will increase child compliance, and that praise 
may be no more effective than other forms of attention.

The Effects of Enthusiasm on Compliance and General Behavior

In addition to the question of whether praise increases appropriate behavior, some research has examined whether enthusiasm is the key to increasing appropriate behavior. Burts, McKinney, and Burts (1985) found that when teachers frequently used enthusiasm with typical children, the children were "more attentive, interested, and responsive" (p. 19). Conversely, teachers who infrequently used enthusiasm had children that were seen as inattentive and unresponsive. Therefore, it can be surmised that when one is highly enthusiastic, a child will be more responsive than when one uses low levels of enthusiasm. In a study of typical children by Zahn-Waxler and Radke-Yarrow (1975), mothers were asked to get their children to imitate their behaviors. Mothers' modeling behaviors were then coded, and it was found that children's imitation was positively associated with the enthusiasm in the mothers' modeling (Zahn-Waxler $\&$ Radke-Yarrow). Thus, based on these results, it is suggested that enthusiasm may be associated with compliance, and with increasing general behavior.

Although there are no studies directly evaluating the effect of enthusiasm on compliance, there is some theoretical work that suggests a correlation between enthusiasm and compliance. For example, Zentall's (1975) theory of optimal stimulation supports the idea that the level of enthusiasm is associated with noncompliance. The theory indicates that each person has a different level of optimal stimulation, or arousal, and each person will try to maintain their particular optimal level of stimulation (Zentall). Zentall believes that "if an optimal stimulation theory is correct, then environments or tasks 'low' in stimulation should be more likely to be associated with hyperactive behavior than those higher in stimulation" (p. 553). These include 
such disruptive behaviors as: distractability, poor school performance, and short attention span. Thus, children in situations with low levels of enthusiasm are likely to perform more poorly, and get distracted more easily than children in situations with high levels of enthusiasm. Several studies support the theory of optimal stimulation by showing that underaroused children perform better in environments with high levels of stimulation (Zentall et al., 1985; Zentall \& Keuczek, 1988; Zentall \& Shaw, 1980; and Zentall \& Zentall 1983). In other words, underaroused children who are in situations with low stimulation will tend to have increased levels of hyperactive behavior, and, thus exhibit more disruptive behavior. Situations involving low levels of enthusiasm, by definition, have a low stimulation value. Therefore, it can be inferred that low levels of enthusiasm also produce disruptive behavior which could include noncompliance.

\section{$\underline{\text { Summary }}$}

In sum, the literature makes some suggestions about compliance and general behavior, but there currently is no literature that specifically examines which aspects of social attention (verbal and non-verbal) increase behavior for children with typical behavior versus those with behavior problems. In other words, there is no literature to suggest the differential effects the factors of enthusiasm versus description versus praise in typical and behavior problem children.

\section{$\underline{\text { Purpose }}$}

The purpose of the present study was to examine the effects of enthusiastic praise, nonenthusiastic praise, and non-enthusiastic description on child compliance and general behavior in children with disruptive behavior problems and typical children. No enthusiastic description group was used in this study because the effect of enthusiasm on child behavior could be determined by comparing the non-enthusiastic praise group and the enthusiastic praise group. 
The study reexamined the issue of praise, and whether praise affects compliance in typical children and in children with behavior problems. New information was provided with regard to differing types of attention on compliance levels and increases in general behavior. Compliance and increases in general behavior were assessed to determine if enthusiasm affects children's behaviors and if it differs with regard to children with typical behavior versus those with behavior problems. This study also compared children with typical behavior and those with behavior problems to examine how they responded to receiving attention for general behavior (i.e., Marble-in-the-Hole Game) versus receiving attention for compliance.

Hypothesis One: It was hypothesized that when children received enthusiastic praise, they would be significantly more compliant and increase the number of marbles dropped in the least-preferred hole than when children received non-enthusiastic praise or non-enthusiastic description, regardless of behavior problems. This was based on previous research that suggested that stimulation is rewarding, and thus, children will exhibit more disruptive and unresponsive behaviors when there are low levels of stimulation (Burts et al. 1985; Zentall 1975; Zentall et al, 1985; Zentall \& Keuczek, 1988; Zentall \& Shaw, 1980; and Zentall \& Zentall 1983). Thus, the component of enthusiasm should produce less disruption and more compliance in children.

Hypothesis Two: It was hypothesized that children with behavior problems would not show significant improvement in their behavior when they were simply praised for compliance without enthusiasm. This was expected because it has been shown that children with disruptive behaviors do not respond to attention in the Compliance Test without the use of time out (Budd et al., 1976; Eisenstadt et al., 1993; Roberts et al., 1981). Therefore, there should be no 
difference in compliance rates for children exhibiting disruptive behavior when their compliance was praised versus when their compliance was described.

Hypothesis Three: Conversely, assuming no ceiling effect, it was proposed that children with typical behavior would show significant improvement in their behavior when they were simply praised for compliance without enthusiasm. This was proposed because it has been shown that a function of compliance for typical children is social attention. For example, previous studies have shown that typical children increase behavior in the Compliance Test without the use of time out (Parpal \& Maccoby 1985). Thus, a significant improvement in compliance was expected for typical children when their compliance was praised rather than described.

Hypothesis Four: It was hypothesized that children with behavior problems would have high rates of general behavior when they were praised for that behavior without enthusiasm. This was expected because previous studies have shown that children with behavior problems respond favorably to praise for general behavior (Roberts, 1985). Thus, it follows that the children exhibiting disruptive behaviors should drop marbles in the least-preferred hole more often in the Marble-in-the-Hole Game after receiving praise, than when their behavior was simply described.

Hypothesis Five: Assuming no ceiling effect, it also was expected that typical children would have high rates of general behavior when they were praised for that behavior without enthusiasm. This hypothesis was based on previous literature that has shown that typical children improved their behavior in the Marble-in-the-Hole Game (which measures general behavior) when they were praised (Bernhardt \& Forehand, 1975). 
Method

Setting and Participants

$\underline{\text { Setting }}$

Data were collected in 10 local head-start centers. The participants were removed from their regular classroom, and all procedures were conducted in a separate room away from the other children.

\section{Participant Selection}

Parental informed consent was obtained for 293 children, and only these children were considered for participation in the study. Fifteen children, exhibiting disruptive behaviors, and fifteen children exhibiting typical behavior were selected for participation. Participants were selected and assigned to groups based on teachers' reports on the Conners' Global Index (CGI, Conners, 1997). The 15 children with the highest scores on the CGI were assigned to the disruptive behavior group (t-score $>65$ ), and the 15 children with the scores that most closely approximate the average (t-score from 45-55), as rated by the CGI, were assigned to the typical group (Conners). Considering all of the completed CGI questionnaires (293), only 15 children met the criteria for the disruptive group, and of those 15 children, only 2 were female. In contrast, more than 15 children met criteria for the typical group. Thus, the participants were chosen randomly by a graduate student not involved in the study. However, participants were chosen so that the groups were balanced according to race and gender. The examiner was not informed as to which group the children belonged. The order in which the participants received the enthusiastic praise, non-enthusiastic praise, and non-enthusiastic description conditions was assigned randomly by drawing numbers from a hat. Each participant received each condition one 
time approximately three weeks apart.

\section{$\underline{\text { Participants }}$}

The participants were 30 children from local head-start centers between the ages of 3 and 5 years. Most of the children were 4 years old (60\%), and a few were 3 and 5 years old (20\% each). The mean age of the participants was 4.00. More specifically, the mean age of the participants in the disruptive group was 3.87 , and the mean age of the participants in the typical group was 4.13. An independent samples t-test was conducted to determine if the groups were significantly different with respect to age. The alpha level was set at $\underline{p}<.05$. Results indicated that the mean ages of the groups did not differ significantly, $\underline{\mathrm{t}}(28)=-1.141, \mathrm{p}<.263$. Males made up the majority of the participants $(86.7 \%)$. An equal number of male and female participants were in each group. The participants were primarily Caucasian (90\%). However, $6.7 \%$ of the participants were Bi-racial, and 3.3\% were African American. There was one African American female in the typical group, one Bi-racial male in the typical group, and one Bi-racial male in the disruptive group.

Most of the caregivers of the participants were both their biological mothers and fathers (56.7\%). In addition, most of the participants were from households in which their biological parents were married (43.3\%). Fifty percent of all of the caregivers of the participants were employed, and in $33.3 \%$ of the households, some, but not all, of the caregivers were employed.

\section{$\underline{\text { Measures }}$}

\section{Dependent Variables}

Compliance Test. The Compliance Test was used to rate child compliance to the experimenter's instructions (Bean \& Roberts, 1981). The present study used a method for the 
Compliance Test similar to Roberts (1985), but it was modified in that the participants received either enthusiastic praise, non-enthusiastic praise, or non-enthusiastic description following compliance. Thirty one-step instructions such as, "Please put the doll in the house," were issued by the experimenter while pointing to the correct objects. Then, the experimenter waited silently for 5-seconds while determining compliance. Roberts defined compliance as "the initiation of a continuous motor response during the 5-second post-instruction interval that terminated in grasping the instruction-designated toy" (p. 614). The present research used this same definition. The experimenter responded to compliance with enthusiastic praise, non-enthusiastic praise, or non-enthusiastic description depending on which condition the participant has been assigned (refer to Appendix A for definitions). When delivering praise, the experimenter used a labeled praise (Appendix A), and as suggested by Roberts et al. (1981), the praises given were selected randomly from a list of praise statements that have been balanced by number of syllables in each response to control for the amount of attention provided (Appendix B). Descriptions also were selected randomly from a list of descriptive statements as seen in Appendix B. Immediately after the experimenter's response, another command was given and the same procedure was followed. Noncompliance received no response; the experimenter waited for 5-seconds and then immediately gave the next command. The entire procedure took approximately 7 minutes. The Compliance Test was scored by taking the number of commands complied with and dividing that number by the total number of commands given, and then multiplying by 100 . The result yields the percentage of commands complied with, or the compliance rate.

Brumfield and Roberts (1998, p. 111) compared the clinic task analog, in which parents used their "own style of child management," to the Compliance Test, in which children were 
praised for complying. It was found that the Compliance Test assessed child compliance accurately because it has good observer reliability, and is sensitive to individual differences and socialization, whereas the clinic task analog proved to be inadequate in assessing child compliance levels. The Compliance Test resulted in $69.3 \%$ agreement between observers. Therefore, the Compliance Test was chosen to measure compliance in the current study. Marble-in-the-Hole Game. This procedure was used to measure the effect of enthusiastic praise, non-enthusiastic praise, and non-enthusiastic description on changing a child's general behavior (Bernhardt \& Forehand, 1975). The Marble-in-the-Hole Game is not a compliance test because the child is not given commands with which to comply. Instead, the child is simply asked to drop marbles into holes and is given attention for dropping the marbles into a particular hole. Thus, this game does not measure compliance, but measures general behavior.

The current study used a modified version of Bernhardt and Forehand's (1975) procedure in that the basic premise of the game was identical, but the experimenter reaction to a marble drop in the least-preferred hole was modified by the three previously mentioned conditions. This game consists of a (jar/box) with two holes in the top: one green, and one red.

At the beginning of this procedure, the child was told "Now, we have a job to do." Next, the experimenter handed the marbles one at a time to the child and asked the child to sit in a chair and drop marbles into either hole. There was a 3-minute baseline period during which the examiner observed which hole the child prefered to drop the marbles into the least, and recorded it on a coding sheet (see Appendix C). After the baseline period, the examiner enthusiastically praised, non-enthusiastically praised, or non-enthusiastically described the child's least-preferred hole for 6 minutes, depending on the participant's assigned condition. Dropping a marble into 
the preferred hole received no response. The examiner silently counted for 5 seconds before giving the child another marble. The statements given in each condition were balanced by number of syllables in each response to control for the amount of attention provided (Appendix D). The enthusiastic praise group received labeled praises with high levels of enthusiasm. The non-enthusiastic praise group received the same statements, only the enthusiasm level was low. The non-enthusiastic description group received similar statements containing the same number of syllables, but without a praise word and without enthusiasm.

Bernhardt and Forehand's (1975) procedure also was modified concerning off-task behavior. In the present study, if the participant engaged in off-task behavior, the experimenter prompted the child by saying, "Please put the marble in a hole." The experimenter then silently counted to 5 to give the participant enough time to complete the command. If the participant's behavior did not get back on task, the experimenter repeated the prompt again and waited 5 seconds for a response. The experimenter prompted the participant up to 3 times. Then, the experimenter ignored the participant until his or her behavior became on task, or the time limit of 6 minutes had expired.

The Marble-in-the-Hole Game was scored by taking the number of marbles dropped in the least-preferred hole in the experimental period, and dividing that number by the total number marble drops in the experimental period, and then multiplying by 100 . The result yields the percent of marbles dropped in the least-preferred hole.

\section{$\underline{\text { Participant Selection Measures }}$}

Conners' Global Index (CGI). This is a shortened version of Conners' (1969) original scale which had 39 items. The CGI has 10 items that measure general child psychopathology. It 
contains disruptive behaviors rated on a 4-point Likert scale ranging from "not at all" (0) to "very much" (3). This measure is useful because it is sensitive to detecting behavioral changes due to treatment, and it requires a short amount of time to administer (Conners, 1997). Also, Margalit (1983) found that this measure demonstrates high inter-rater reliability (.85) and high internal consistency (.90). Several studies lend further support to the reliability, validity, and usefulness of this measure (e.g., Brown \& Wynne, 1982; Diamond \& Deane, 1990; DuPaul, 1991; DuPaul \& Barkley, 1992; Epstein \& Nieminen, 1983). The teachers were asked to complete a CGI for every student in their class who had parental informed consent (Appendix E).

Demographic Questionnaire. The teachers were asked to complete a short demographic questionnaire on each participant in the proposed study (Appendix F). The questionnaire included the child's age, sex, race, family dynamics, and family employment. This information was requested in order to determine whether demographic differences existed between the typical and disruptive behavior groups that might confound the results.

\section{$\underline{\text { Integrity and Reliability }}$}

Treatment Integrity Measures. Treatment integrity assessed the accuracy of the experimenter in her administration of the enthusiastic praise, non-enthusiastic praise, and nonenthusiastic description conditions for every session. This was measured by using the treatment integrity checklist coding sheets for the Compliance Test and the Marble-in-the-Hole Game (Appendix C, G, \& H). A score of $90 \%$ or greater was considered an accurate and successful implementation of that condition. At no time did the experimenter fall below $90 \%$ accuracy on any of the sessions (range $93.3 \%-100 \%$ ). The average treatment integrity was $99.8 \%$.

Training coders. Two advanced undergraduates were trained as research assistants to 
code videotapes of the sessions for compliance, marble dropping, enthusiasm, praise, and descriptions using pilot training tapes. The primary investigator trained research assistants by providing them with information and definitions (Appendix A) of the above-mentioned behaviors, and by using pilot training videotapes. The research assistants and the primary investigator jointly coded the videotapes at the beginning of data collection so that the research assistants learned to code the tapes reliably. Then, the research assistants independently obtained $80 \%$ reliability with the graduate student on separate training videotaped observations for all measures.

Interobserver reliability. Reliability was assessed throughout the data collection process for $25 \%$ of the observations drawn evenly across all sessions and participants on the following variables: enthusiasm, praise, description, compliance, and marble dropping. If reliability fell below .75 Kappa on any of these observations, the research assistants were retrained before coding continued. The Kappa fell below .75 three times (range .000 - 1.00). on the Marble-inthe-Hole Game, and the coders were retrained. The Kappas obtained on these three sessions were used in the calculations of the overall Kappa coefficients, and these sessions were recoded by group consensus to obtain correct compliance and marble dropping percentages for data analysis. The research assistants were not informed to the participants' group assignment and the study's hypotheses. Interobserver reliability of the two research assistants was calculated using the Kappa statistic to ensure good coding. This Kappa level was chosen because according to Fleiss (1981) Kappas of .75 or greater are considered excellent. The mean Kappa coefficient scores for each category were as follows for the Compliance Test: enthusiasm $=1.00$, praise $=$ 1.00 , description $=1.00$, compliance $=1.00$. The mean Kappa coefficient scores for each 
category were as follows for the Marble-in-the-Hole Game: enthusiasm $=1.00$, praise $=1.00$, description $=1.00$, marble dropping $=.85$. The Kappa coefficient score for marble dropping was .85 because of measurement error.

\section{$\underline{\text { Procedure }}$}

\section{$\underline{\text { Experimental Conditions }}$}

The study was a within-subject design in which three conditions were implemented (enthusiastic praise, non-enthusiastic praise, and non-enthusiastic description) to two groups: children exhibiting typical behavior and children exhibiting disruptive behavior (refer to Appendix I for a chart). The participants received each task in each condition approximately 3 weeks apart to minimize carry over effects. Enthusiasm was defined as "sudden changes from rapid excited speech to a whisper, good eye contact and variations in expression; quick and demonstrative movements of the body, head, arms, and face; large body movements; vibrant, demonstrative facial expressions with quick and sudden changes... and an overall high energy level" (Burts et al., 1985, p. 22). Non-enthusiasm was defined as "speaking in a monotone voice; exhibiting little eye contact and expression; utilizing few gestures and body movements; showing little facial expressions... and generally appearing lethargic" (Burts et al., p. 21).

The first part of the session consisted of a 3-minute free play period during which time the child was able to play with any toy on the table while the examiner simulated filling out questionnaires. This allowed the child to become acquainted with the setting, and involved with the toys. The same set of toys (including a garage with cars, legos, a dollhouse with dolls, and a barn with animals) was used for each participant, and the toys also were set up in the same manner on a table for each participant. These toys remained on the table for the entire procedure. 
The second and third parts of the session consisted of the Compliance Test and the Marble-inthe-Hole Game given in random order to the participants. In the Compliance Test, one of the three conditions was implemented following compliance, and no response was given for noncompliance. In the Marble-in-the-Hole Game, one of the three conditions was used for dropping the marble in the least-preferred hole, and no response was given for dropping the marble in the preferred hole. Lastly, the examiner had 5 minutes of play therapy using the “pride” skills as described by McNeil (1998). These skills include praise, reflection, imitation, description, and enthusiasm. This was done in accord with the APA ethics code 4.09 so that the child would not have a "bad feeling" when leaving the session and returning to the classroom (Canter, Bennett, Jones, \& Nagy, 1996). The child was given a small prize (e.g., sticker) to facilitate satisfaction with the procedure that was held by the teacher until the end of the day. The entire procedure took approximately 25 minutes for each of the three administrations.

The entire procedure was videotaped and later coded. Each statement that the examiner issued was coded for enthusiasm, praise and description in the Compliance Test and the Marblein-the-Hole Game using provided coding sheets (Appendix C, G, \& H). Children's compliance to commands and marble-dropping behavior also was coded using provided coding sheets (Appendix C, G, \& H).

Results

Initially, a 2 (Group) X 3 (Condition) X 2 (Task) repeated measures MANOVA was conducted to determine if there was a three-way interaction. Results indicated that the condition $\mathrm{X}$ group $\mathrm{X}$ task interaction was not significant, $\underline{\mathrm{F}}(2,20)=.450, \underline{\mathrm{p}}<.644$. Because of concerns regarding missing data, it was decided to conduct two separate 2 (group) X 3 (condition) repeated 
measures MANOVAs, one for each task. The concern pertained to the fact that there were 10 missing data points in the Marble-in-the-Hole Game across seven participants which would have meant that all of the data for those seven participants in both tasks would have been unusable because the participants never came into contact with the contingency for dropping the marble in the least-preferred hole. In other words, the participants never received social attention for their behavior. Therefore, these sessions were unusable, and thus were missing values. There were two reasons why children never received social attention for the Marble-in-the-Hole Game: (a) the child was off-task and never dropped a marble into either hole during the procedure (three of the missing data points), and (b) the child dropped marbles into a hole, but never the leastpreferred hole (seven of the missing data points). Table 2 includes the specific conditions, groups, and reasons for the missing values. However, conducting separate MANOVAs for each task allowed the data for those participants to be used in the Compliance Test.

\section{Compliance Test}

To determine whether the participants differed with respect to their compliance percentages in each of the three conditions (i.e., non-enthusiastic praise, enthusiastic praise, and non-enthusiastic description), a 2 (Group) X 3 (Condition) repeated measures MANOVA was conducted. The alpha level was set at $p<.05$. A significant difference was found between the conditions across groups, $\underline{\mathrm{F}}(2,27)=4.085, \underline{\mathrm{p}}<.028$. Post-hoc analyses were conducted using pairwise comparisons with estimated marginal means, which are LSD tests, to determine which conditions significantly differed from each other. Results indicated that the non-enthusiastic praise condition and the non-enthusiastic description condition were significantly different across groups (i.e., disruptive and typical groups combined) with respect to compliance, $p<.010$. The 
percent compliance was higher in the non-enthusiastic description condition than the nonenthusiastic praise condition. The between-subjects factor, groups (i.e., disruptive, typical), was not found to be significant, $\underline{\mathrm{F}}(1,28)=3.846, \mathrm{p}<.060$. However, there was a trend suggesting lower compliance rates in the disruptive group than in the typical group. In addition, the condition $\mathrm{X}$ group interaction was not found to be significant, $\underline{\mathrm{F}}(2,27)=.119, \underline{\mathrm{p}}<.888$. Means and standard deviations are presented in Table 1.

\section{Marble-in-the-Hole Game}

Ten data points were missing in this task across the three conditions (i.e., six in the disruptive group, four in the typical group) (see Table 2). Therefore, two MANOVAs were conducted. The first MANOVA was conducted excluding all data from participants who had a missing data point, and the second MANOVA was conducted with the missing data replaced using the series mean procedure independently for the disruptive and the typical groups.

To determine whether the participants differed with respect to their general behavior (i.e., percent of marbles dropped in least-preferred hole) in each of the three conditions (i.e., nonenthusiastic praise, enthusiastic praise, and non-enthusiastic description), a 2 (Group) X 3 (Condition) repeated measures MANOVA was conducted with the missing data points (i.e., excluding all data from participants who had a missing data point). The alpha level was set at $\mathrm{p}$ $<.05$. Results indicated that there were no significant differences found (all p's > .05). Means and standard deviations are presented in Table 3.

A second 2 (Group) X 3 (Condition) repeated measures MANOVA was conducted to determine if the results would be consistent if there was less missing data. With this MANOVA, the missing data were replaced using the series mean procedure independently for the disruptive 
and the typical groups. Results indicated that significant differences were found between the conditions across groups, $\underline{\mathrm{F}}(2,27)=4.097, \underline{\mathrm{p}}<.028$. The differences between the means were in the same direction as the results that were found when the missing data points were not replaced. Therefore, post-hoc analyses were conducted using pairwise comparisons with estimated marginal, which are LSD tests, means to determine which conditions significantly differed. Results indicated that the enthusiastic praise condition and the non-enthusiastic description condition were significantly different across groups (i.e., disruptive and typical groups combined) with respect to marble dropping, $\mathrm{p}<.007$. More specifically, the percent of marbles dropped in the least-preferred hole was significantly higher in the enthusiastic praise condition than the nonenthusiastic description condition. The between-subjects factor, groups (i.e., disruptive, typical) was not found to be significant, $\underline{\mathrm{F}}(1,28)=.021, \underline{\mathrm{p}}<.887$. In addition, the condition $\mathrm{X}$ group interaction was not found to be significant, $\underline{\mathrm{F}}(2,27)=2.226, \underline{\mathrm{p}}<.127$. Means and standard deviations are presented in Table 3.

\section{$\underline{\text { Satiation Effects }}$}

A series of paired sample t-tests were conducted to determine if satiation effects occurred in each condition in the Compliance Test. The Compliance Test was divided into thirds, and compliance percentages were calculated for each third. $\underline{T}$-tests were conducted on the first third and second third, second third and third third, and first third and third third of each conduction. Therefore, nine total t-tests were conducted. The alpha level was set at $\mathrm{p}<.05$. Results indicated that there were no significant differences found (all p's $>.05$ ).

\section{Discussion}

The main goal of this study was to examine the effects of enthusiastic praise, non- 
enthusiastic praise, and non-enthusiastic description on child compliance and general behavior in children with disruptive behavior problems and typical children. More specifically, this study was conducted to determine how different aspects of attention (i.e., praise, enthusiasm, and description) affected children's responses in a task measuring compliance compared to a task measuring general behavior, and if there were differences between the groups (i.e., disruptive vs. typical).

The Compliance Test and the Marble-in-the-Hole Game were conducted with 15 typical children and 15 children exhibiting disruptive behavior, as determined by a teacher-completed CGI, in 10 local Head Start classrooms. Children received attention (i.e., non-enthusiastic praise, enthusiastic praise, non-enthusiastic description) for compliance or marble-dropping in their least- preferred hole. There were three main findings of this study. First, the participants (i.e., disruptive and typical combined) responded differently to the three types of attention in the Compliance Test versus the Marble-in-the-Hole Game. The second finding was that children with disruptive behavior and children with typical behavior were not significantly different in their responses to the three types of attention in the Marble-in-the-Hole Game and the Compliance Test. Third, a trend indicated that the children exhibiting disruptive behaviors were less compliant overall than the typical children in the Compliance Test.

$$
\text { Main Findings }
$$

Summary of Findings Concerning Hypotheses

Hypothesis one stated that the participants (disruptive and typical) would have significantly higher responding in the Compliance Test (compliance) and the Marble-in-the-Hole Game (general behavior) in the enthusiastic praise condition as compared to the other two 
conditions. This hypothesis was supported with respect to the Marble-in-the-Hole Game, but not with respect to the Compliance Test. In the Compliance Test, the participants were significantly more compliant in the non-enthusiastic description condition than the non-enthusiastic praise condition.

Hypothesis two stated that there should be no significant difference in the nonenthusiastic praise condition and the non-enthusiastic description condition with respect to compliance for the children in the disruptive group. In contrast, hypothesis three stated that there

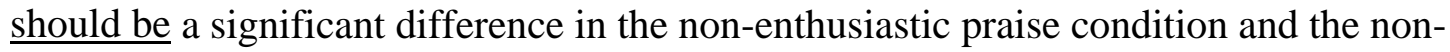
enthusiastic description condition with respect to compliance for the children in the typical group in that they should have higher rates of compliance in the non-enthusiastic praise condition. Two results failed to support these hypotheses. First, there were no significant group by condition interaction effects for the Compliance Test. Second, the significant finding that was obtained for the combined group was unexpected in that the participants (disruptive + typical) actually complied the most in the non-enthusiastic description condition.

Hypotheses four and five stated that children with disruptive behaviors and children with typical behaviors should have higher rates of marbles dropped in the least-preferred hole (general behavior) in the non-enthusiastic praise condition than in the non-enthusiastic description condition. These hypotheses were not supported because there was no significant difference found between these two conditions for either of the groups. However, there was a significant difference found between the enthusiastic praise condition and the non-enthusiastic description condition which lends some support to the idea that children would respond more to praise for general behavior. 


\section{Responding Across Tasks in Both Groups Combined (i.e., Disruptive + Typical)}

The results indicated that the effects of the three attention consequences were different across tasks. In the Compliance Test, the combined group (disruptive + typical) responded significantly more often in the non-enthusiastic description compared to the non-enthusiastic praise condition, whereas in the Marble-in-the-Hole Game, the combined group (disruptive + typical) responded significantly more often in the enthusiastic praise condition compared to the non-enthusiastic description condition. These findings suggest that these two tasks are indeed measuring different behaviors (i.e., compliance and general behavior). This may be because the Compliance Test involves commands whereas the Marble-in-the-Hole Game does not. However, the Marble-in-the-Hole Game may not be a clear measure of general behavior. In other words, it may have some aspect of compliance to it. With regard to the three aspects of attention explored in the current study, it appears that non-enthusiastically describing compliance and enthusiastically praising general behavior are the most effective types of attention to increase desired behavior in children exhibiting typical behaviors as well as children exhibiting disruptive behaviors. Soutor, Houlihan, and Young (1994) also found differences when they rewarded compliance as compared to when they rewarded behaviors other than compliance (i.e., attending). However, their results were different from the results found in the current study. Soutor et al. found that when social praise was paired with edibles, compliance increased, whereas it had no significant affect on attending.

In the Compliance Test, the children may have been more compliant in the nonenthusiastic description condition for two possible reasons: (a) non-enthusiastic description may be a discriminative stimulus for punishment; and (b) there may be a satiation effect when 
praising at high rates. With regard to the discriminative stimulus possibility, during the nonenthusiastic description condition, the experimenter simply responded to the child's compliance with a descriptive statement given in a monotonous tone of voice with no affect (e.g., "You put the car in the garage, you did."). In addition, the Compliance Test is basically a clean-up task in which direct commands are given. Through past interactions, children may have learned that noncompliance in a clean-up situation with an adult who is non-expressive may be associated with punishment. Thus, non-enthusiastic description may have been a discriminative stimulus to listen so as to avoid punishment. In other words, the children's behavior was under stimulus control, and they were more compliant to non-enthusiastic description because it was more reinforcing to avoid punishment (negative reinforcement) than to receive praise (positive reinforcement).

A second possibility for the obtained results may have been a satiation effect. The children could have been satiated by praise in the praise conditions, and therefore, they decreased their responding because their attentional needs were met. This may have been because the children received praise continuously for compliance (i.e., FR 1 schedule of reinforcement), and once they became satiated by praise, they decreased their compliant behavior. This would have led to lower compliance rates in the praise conditions. In contrast, in the non-enthusiastic description condition, the participants may have continued to comply in an attempt to receive praise, which they never received. Therefore, they were more compliant in this condition because they were working for praise to meet their attentional needs. However, analyses conducted to determine satiation effects revealed that there were no satiation effects in any of the conditions for the Compliance Test. 
Praise and enthusiasm. It was expected that children would have higher rates of compliance and general behavior when their behavior was enthusiastically praised than when their behavior was non-enthusiastically praised or non-enthusiastically described. Thus, it was expected that enthusiasm and praise would lead to higher responding in both tasks. However, the findings indicated that children had significantly higher rates of dropping the marble in the leastpreferred hole in the enthusiastic praise condition than in the non-enthusiastic description condition, but that enthusiasm and praise did not lead to higher rates of compliance.

The finding concerning the Marble-in-the-Hole Game supports previous research suggesting that both children exhibiting disruptive and typical behaviors increase their marbledropping in the least-preferred hole when praised for that behavior (Bernhardt \& Forehand, 1975; Roberts, 1985). In addition, Zentall and colleagues' research has indicated that high levels of stimulation are more rewarding than low levels of stimulation which supports the finding that the children responded appropriately more often in the enthusiastic praise condition. Thus, in a task that measures general behavior, enthusiastic praise appears to be effective in increasing desired behavior.

In contrast, these same results may not have been found in the Compliance Test because the function of compliance may be different than the function of marble dropping. Attention may be the function of marble dropping because the Marble-in-the-Hole Game is a task in which no commands are given and the child simply receives attention for dropping marbles into holes. Thus, it is not a discipline-like task, but a game-like task. In other words, the function of noncompliance may have affected responding in each of the conditions. For example, research suggests that one function of noncompliance is escape from demands (Mace \& Belfiore, 1990; 
Reimers et al., 1993; Russo, Cataldo, \& Cushing, 1981), and another function of noncompliance is attention (Reimers et al., 1993; Rortvedt \& Miltenberger, 1994; Russo, Cataldo, \& Cushing, 1981). Therefore, "if escape from demands is a very high-quality reinforcer, increasing social reinforcement for compliance may not be sufficient to reduce escape-motivated behavior and increase compliance" (Mace \& Belfiore, 1990, p. 513). Enthusiasm and praise may have been less reinforcing than task avoidance, and thus, the children were less compliant in the enthusiastic praise and non-enthusiastic praise conditions. In addition, they may have been more compliant in the non-enthusiastic description condition because it served as a discriminative stimulus for punishment, or because there was a satiation effect when they were praised at high rates.

Enthusiasm and praise alone were found to be less effective for compliance. However, if a mildly aversive punishment (i.e., time out) was used as a negative consequence in addition to the positive consequences of enthusiasm and praise, compliance rates may have been higher. Previous research has supported this idea (Budd et al., 1976; Eisenstadt et al., 1993; Roberts et al., 1981). In addition, these findings support the two-phase parent training model such as the one used in PCIT (Hembree-Kigin \& McNeil, 1995) in that enthusiasm and praise are more effective in non-discipline tasks (i.e., Marble-in-the-Hole Game) and that they alone are not as effective for compliance. Therefore, in PCIT, two phases are used; one focusing on positive relationshipbuilding skills (e.g., praise, enthusiasm), and the other focusing on compliance and discipline. Responding in the Marble-in-the-Hole Game in the Disruptive versus Typical Group

Similar to what was expected, children in the typical group and children in the disruptive group did not respond significantly different from each other with respect to general behavior. 
Previous studies have shown that children with behavior problems (Roberts, 1985) and children with typical behavior (Bernhardt \& Forehand, 1975) respond favorably to praise for general behavior. Therefore, it seems that because the Marble-in-the-Hole Game is not measuring compliance (which is one of the areas in which children exhibiting disruptive behaviors have problems), responding should have been similar in both groups (disruptive and typical), and it was found that both children exhibiting disruptive behaviors, and children exhibiting typical behaviors responded significantly more in the enthusiastic praise condition than in the nonenthusiastic description.

Responding in the Compliance Test in the Disruptive versus Typical Group

The children in the typical group and the children in the disruptive group did not respond significantly differently from each other to the three types of attention on the Compliance Test. However, there was a possible trend $(\underline{p}<.06)$ that the compliance rates of the children with disruptive behaviors were lower than the compliance rates of the children with typical behaviors. Previous studies have indicated that typical children have higher rates of compliance than children with disruptive behaviors when they receive social attention for compliance with no aversive consequence (e.g., time out) (Budd et al., 1976; Eisenstadt et al., 1993; Parpal \& Maccoby, 1985; Roberts et al., 1981). In the current study, this possible trend may not have reached significance because the children were not clinically-referred as they were in previous studies (e.g., Roberts, 1985), and because the experimenter had no prior relationship with the children unlike the experimenters (i.e., parents, teachers) in previous studies (e.g., Roberts, 1985). Another reason that the possible trend may not have reached significance may have been because it has been shown that children with disruptive behavior problems exhibit more 
disruptive behaviors in group situations compared to individual situations (Nidiffer, Ciulla, Russo, \& Cataldo, 1983). Therefore, the compliant behavior of the children with disruptive behaviors may have been elevated because the task was conducted individually, leading to nonsignificant differences in their compliance percentages compared to those of typical children. However, the possible trend is important because the direction of the means (i.e., disruptive lower than typical) is consistent with previous research using the Compliance Test (e.g., Parpal \& Maccoby, 1985; Roberts, 1985).

\section{Methodological Limitation and Suggestions for Future Directions}

One limitation of this study was that there were ten missing data points across conditions in the Marble-in-the-Hole Game because the participants never came into contact with the contingency for dropping the marble in the least-preferred hole. Because $12.2 \%$ of the data was missing for the Marble-in-the-Hole Game, the values were replaced using a series mean procedure separately for the disruptive group and the typical group for each condition. This is a serious limitation to the current study because this procedure is intended to be used with time series data, and the data of the current study were independent repeated measures. Therefore, the results of the Marble-in-the-Hole procedure should be interpreted cautiously, and only suggest what could have happened if the data were not missing. It is possible that different results may have been obtained if all of the data had been collected and analyzed.

One of the reasons that some of the data were missing was because some of the children exhibited off-task behaviors before the testing phase of the game. The baseline period of the Marble-in-the-Hole Game was 3 minutes and the testing period was 6 minutes. For preschool children, especially preschool children with disruptive behaviors, 3 minutes at one task is a long 
time, and they, therefore exhibited off-task behaviors before the testing period began. Thus, it is recommended that, in the future, the baseline period of the Marble-in-the-Hole Game be eliminated for young children because it may become very boring for them. It is suggested that the hole that is socially reinforced be chosen randomly rather than using the "least preferred" criterion.

Another concern with the use of the Marble-in-the-Hole Game is that the validity of the procedure is unknown. No studies have reported any validity data concerning this procedure. Therefore, the results found with the Marble-in-the-Hole Game may not be valid. In addition, this task may not be a clear measure of general behavior. More specifically, it may contain some aspect of compliance. Thus, future research using this task should focus on its validity. In addition, other measures of general behavior should be used to determine if the Marble-in-theHole game produces the same results as other measures.

Another limitation of the current study was that the experimenter was unknown to the participants and they may have responded differently if their teacher or their caregiver was conducting the procedures with them. In other words, their rates of compliance and general behavior may have been different because the relative effectiveness of attention may be affected by one's learning history with a particular person. Therefore, it is suggested that this study be systematically replicated with adults with which the participants are familiar to determine if the same results would be found.

Since the participants were not clinically-referred, the results of this study may have been different if the participants were clinically-referred. More specifically, the behaviors of the participants may have been mild compared to children with diagnosed behavior problems. 
Systematic replication of this study is suggested with children with diagnosed behavior problems to determine if the same results would be found.

Sample size was a problem in the current study. Thirty participants (15 typical and 15 disruptive) were included in the current study, which may have limited the resulted that were obtained. More specifically, some results may have been significant if the sample size was larger. Future research in this area should use large sample sizes to assure that there is enough power to detect all significant results.

Functional assessments were not conducted in the current study to determine the function of the children's noncompliance (i.e., attention, escape/avoidance). Thus, it is recommended that future studies focus on conducting a functional analysis for each child in the study to determine if the different types of attention will function as reinforcers for the participants.

In the current study, no enthusiastic description condition was implemented because it was thought that the effects of enthusiasm on behavior could be determined by comparing the non-enthusiastic praise condition and the enthusiastic praise condition. However, because the results indicated that responding in the non-enthusiastic description condition was significantly different from other conditions in both tasks, it may have been helpful to compare an enthusiastic description condition to the non-enthusiastic description condition to determine if there would have been any differences. Thus, it is suggested that future research compare these two conditions with respect to compliance and general behavior.

Finally, this study has interesting clinical implications. It suggests that enthusiastic praise is helpful to use to increase general behavior (i.e., behavior other than compliance), probably because the function of general behavior is often for attention. Thus, parent training programs 
should continue to teach parents to use enthusiastic praise to increase appropriate general behavior like sitting quietly because it seems to be an effective type of attention to use in that situation. This study also suggests that compliance is different than general behavior and that different types of attention work to increase compliance than those that work to increase general behavior. Parent training programs teach parents to remain calm and robotic using a neutral tone of voice when they discipline. This type of attention is similar to non-enthusiastic description, which the current study has shown is the most effective type of attention to use to increase compliance. Thus, this study suggests that parent training programs have been teaching parents useful skills to use with children disruptive exhibiting disruptive behaviors. Therefore, future research with children referred for disruptive behavior problems should focus on comparing the consequence of non-enthusiastic description for compliance with no attention for compliance to determine which consequence is more reinforcing. Another area that should be researched is the addition of time out to each condition (i.e., non-enthusiastic description, enthusiastic praise, nonenthusiastic praise) to determine if appropriate behavior increases, and which type of attention, when added to time out, results in the highest levels of compliance. 


\section{References}

Barkley, R. A. (1987). Defiant children: A clinician's manual for parent training. New York: Guilford Press.

Bean, A. W., \& Roberts, M. W. (1981). The effect of time out release contingencies on changes in child noncompliance. Journal of Abnormal Child Psychology, 9, 95-105.

Bernhardt, A. J., \& Forehand, R. (1975). The effects of labeled and unlabeled praise upon lower and middle class children. Journal of Experimental Child Psychology, 19, 536-543.

Brown, R. T., \& Wynne, M. E. (1982). Correlates of teacher ratings, sustained attention, and impulsivity in hyperactive and normal boys. Journal of Clinical Child Psychology, 11, 262267.

Brumfield, B. D., \& Roberts, M. W. (1998). A comparison of two measurements of child compliance with normal preschool children. Journal of Clinical Child Psychology, 27 (1), 109-116.

Budd, K. S., Green, D. R., \& Baer, D. M. (1976). An analysis of multiple misplaced parental social contingencies. Journal of Applied Behavior Analysis, 9 (4), 459-470.

Burts, D. C., Warren McKinney, C., \& Burts, B. L. (1985). Effects of teacher enthusiasm on three- and four-year-old children's acquisition of four concepts. Theory and Research in Social Education, 13 (1), 19-29.

Canter, M. B., Bennett, B. E., Jones, S. E., \& Nagy, T. F. (1996). Ethics for Psychologists: A commentary on the APA Ethics Code. Washington DC: American Psychological Association.

Cohen, J. (1988). Statistical power analysis for the behavioral sciences $\left(2^{\text {nd }}\right.$ ed.). New 
York: Academic Press.

Conners, C. K. (1969). A teacher rating scale for use in drug studies with children. American Journal of Psychiatry, 126, 884-888.

Conners, C. K. (1997). Conners' Rating Scales - Revised. New York: Multi-Health Systems Inc.

Davies, G. R., McMahon, R. J., Flessati, E. W., \& Tiedemann, G. L. (1984). Verbal rationales and modeling as adjuncts to a parenting technique for child compliance. Child Development, 55, 1290-1298.

Diamond, J. M., \& Deanne, F. P. (1990). Conners' Teachers' Questionnaire: Effects and implications of frequent administration. Journal of Clinical Child Psychology, 19, 202-204.

DuPaul, G. J. (1991). Parent and teacher ratings of ADHD symptoms: Psychometric properties in a community based sample. Journal of Clinical Child Psychology, 29, 245-253.

DuPaul, G. J., \& Barkley, R. A. (1992). Situational variability of attention problems: Psychometric properties of the Revised Home and School Situations Questionnaire. Journal of Clinical Child Psychology, 21, 178-188.

Edelbrock, C., \& Rancurello, M. D. (1985). Childhood hyperactivity: An overview of rating scales and their applications. Clinical Psychology Review, 5, 429-445.

Eisenstadt, T. H., Eyberg, S., McNeil, C. B., Newcomb, K., \& Funderburk, B. (1993). Parent-child interaction therapy with behavior problem children: Relative effectiveness of two stages and overall treatment outcome. Journal of Clinical Child Psychology, 22 (1), 42-51.

Epstein, M. H., \& Nieminen, G. S. (1983). Reliability of the Conners' Abbreviated Teacher Rating Scale across raters and across time: Use with learning disabled students. School 
Psychology Review, 12, 337-339.

Eyberg, S. M. (1988). Parent-child interaction therapy: Integration of traditional and behavioral concerns. Child and Family Behavior Therapy, 10, 33-46.

Eyberg, S. M., \& Robinson, E. A. (1982). Parent-child interaction training: Effects on family functioning. Journal of Clinical Child Psychology, 11, 130-137.

Eyberg, S. M., \& Robinson, E. A. (1983). Dyadic Parent-Child Interaction Coding System: A manual. Psychological Documents, 13, Ms. No. 2582. (Available from Social and Behavior Sciences Documents, Select Press, P. O. Box 9838, San Rafael, CA 94912.)

Fleiss, J. L. (1981). Statistical methods for rates and proportions. New York: John Wiley and Sons.

Forehand, R. Gardner, H., \& Roberts, M. (1978). Maternal response to child compliance and noncompliance: Some normative data. Journal of Clinical Child Psychology, 7, 121-124.

Forehand, R., \& McMahon, R. J. (1981). Helping the noncompliant child: A clinician's guide to parent training. New York: Guilford Press.

Forehand, R., Roberts, M. W., Doleys, D. M., Hobs, S. A., \& Resick, P. A. (1976). An examination of disciplinary procedures with children. Journal of Experimental Child Psychology, 21, 109-120.

Hanf, C. A. (1969). A two-stage program for modifying maternal controlling during mother-child (M-C) interaction. Paper presented at the meeting of the Western Psychological Association, Vancouver.

Hembree-Kigin, T. L., \& McNeil, C. B. (1995). Parent-Child Interaction Therapy. New York: Plenum Press. 
Howell, D. C. (1997). Statistical methods for psychology (4 ${ }^{\text {th }}$ ed.). Belmont, CA: Duxbury Press.

Loeber, R., \& Schmaling, K. B. (1985). Empirical evidence for overt and covert patterns of antisocial conduct problems: A meta-analysis. Journal of Abnormal Child Psychology, 12 , $337-352$.

Mace, F. C., \& Belfiore, P. (1990). Behavioral momentum in the treatment of escapemotivated stereotypy. Journal of Applied Behavior Analysis, 23, 507-514.

Margalit, M. (1983). Diagnostic application of the Conners' Abbreviates Symptom Questionnaire. Journal of Clinical Child Psychology, 12, 355-357.

McNeil, C. B. (1998, September). Treatment of behavior problems in young abused children. An invited continuing education workshop for the annual conference of the Public Children's Services Association of Ohio, Columbus, OH.

Nidiffer, F. D., Ciulla, R. P., Russo, D. C., \& Cataldo, M. F. (1983). Behavioral variability as a function of noncontingent adult attention, peer availability, and situational demands in three hyperactive boys. Journal of Experimental Child Psychology, 36, 109-123.

Parpal, M., \& Maccoby, E. E. (1985). Maternal responsiveness and subsequent child compliance. Child Development, 56, 1326-1334.

Pfiffner, L. J., \& O’Leary, S. G. (1987). The efficacy of all-positive management as a function of the prior use of negative consequences. Journal of Applied Behavior Analysis, 20, $265-271$.

Pfiffner, L. J., Rosén, L. A., \& O’Leary, S. G. (1985). The efficacy of an all-positive approach to classroom management. Journal of Applied Behavior Analysis, 18, 257-261. 
Reimers, T. M., Wacker, D. P., Cooper, L. J., Sasso, G. M., Berg, W. K., \& Steege, M. W. (1993). Assessing the functional properties of noncompliant behavior in an outpatient setting. Child and Family Behavior Therapy, 15 (3), 1-15.

Roberts, M. W. (1985). Praising child compliance: Reinforcement or ritual? Journal of Abnormal Child Psychology, 13 (4), 611-629.

Roberts, M. W., Hatzenbuehler, L. C., \& Bean, A. W. (1981). The effects of differential attention and timeout on child noncompliance. Behavior Therapy, 12, 93-99.

Robinson, E. A., \& Eyberg, S. M. (1981). The Dyadic Parent-Child Interaction Coding System: Standardization and validation. Journal of Consulting and Clinical Psychology, 49 (2), $245-250$.

Rortvedt, A. K., \& Miltenberger, R. G. (1994). Analysis of a high-probability instructional sequence and time out in the treatment of child noncompliance. Journal of Applied Behavior Analysis, 27, 327-330.

Russo, D. C., Cataldo, M. F., \& Cushing, P. J. (1981). Compliance training and behavioral covariation in the treatment of multiple behavior problems. Journal of Applied Behavior Analysis, 14, 209-222.

Soutor, T. A., Houlihan, D., \& Young, A. (1994). An examination of response covariation in the behavioral treatment of identical twin boys with multiple behavioral disorders. Behavioral Interventions, 9 (3), 141-155.

Wahler, R. G. (1969). Oppositional children: A quest for parental reinforcement control. Journal of Applied Behavior Analysis, 2 (3), 159-170.

Wahler, R. B., \& Bellamy, A. (1997). Generating reciprocity with conduct problem 
children and their mothers: The effectiveness of compliance teaching and responsive parenting. Journal of Social and Personal Relationships, 14 (4), 549-564.

Webster-Stratton, C. H. (1996). Early intervention with videotape modeling: Programs for families of children with oppositional defiant disorder or conduct disorder. In E. D. Hibbs \& P. S. Jensen. Psychosocial treatments for child and adolescent disorders: Empirically based strategies for clinical practice (pp. 435-474). Washington, DC: American Psychological Association.

Zahn-Waxler C., \& Radke-Yarrow, M. (1975). An observational study of maternal models. Developmental Psychology, 11 (4), 485-494.

Zentall, S. (1975). Optimal stimulation as theoretical basis of hyperactivity. American Journal of Orthopsychiatry, 45 (4), 549-563.

Zentall, S. S., \& Shaw, J. H. (1980). Effects of classroom noise on performance and activity of second-grade hyperactive and control children. Journal of Educational Psychology, 72 (6), 830-840.

Zentall, S. S., \& Zentall, T. R. (1983). Optimal stimulation: A model of disordered activity and performance in normal and deviant children. Psychological Bulletin, 94 (3), 446471.

Zentall, S. S., \& Kruczek, T. (1988). The attraction of color for active attention-problem children. Exceptional Children, 54 (4), 357-362.

Zentall, S. S., Falkenberg, S. D., \& Smith, L. B. (1985). Effects of color stimulation and information on the copying performance of attention-problem adolescents. Journal of Abnormal Child Psychology, 13 (4), 501-511. 
Zentall, S. S., \& Meyer, M. J. (1987). Self-regulation of stimulation for ADD-H children during reading and vigilance task performance. Journal of Abnormal Child Psychology, 15 (4), 519-536. 


\section{Appendix A}

\section{Definitions}

A. Active Ignoring: An explanation is given to the child concerning the reason that he or she will be ignored, and then the examiner turns his or her whole body away from the child, "remains silent, maintains a neutral facial expression, avoids eye contact, and makes no movement in response to the child except to turn away" (Hembree-Kigin \& McNeil, 1995, p. 149).

B. Compliance: "The initiation of a continuous motor response during the 5-second postinstruction interval that terminated in grasping the instruction-designated toy" (Roberts, 1985, p. 614).

B. Description: "A declarative sentence or phrase that gives an account of the objects or people in the situation or the activity occurring during the interaction" (e.g., You put the doll in the house.) (Hembree-Kigin \& McNeil, 1995, p. 149).

C. $\quad$ Enthusiasm: "Sudden changes from rapid excited speech to a whisper, good eye contact and variations in expression; quick and demonstrative movements of the body, head, arms, and face; large body movements; vibrant, demonstrative facial expressions with quick and sudden changes... and an overall high energy level” (Burts et. al., 1985, p. 22).

D. General Behavior: Any behavior other than compliance.

E. Labeled Praise: A labeled praise lets the child know exactly what is liked about his or her behavior because it is specific in that it describes the behavior being praised (Bernhardt \& Forehand, 1975; Eyberg \& Robinson, 1983; Hembree-Kigin \& McNeil, 1995).

F. Noncompliance: No initiation of a motor response to begin obeying an instruction within 
5-seconds.

G. Non-enthusiasm: "Speaking in a monotone voice; exhibiting little eye contact and expression; utilizing few gestures and body movements; showing little facial expressions... and generally appearing lethargic" (Burts et. al., 1985, p. 21). 


\section{Appendix B}

\section{Response statements for Compliance Test.}

The statements that will be given to the enthusiastic, and non-enthusiastic praise groups are as follows:
(a) Thanks for putting the in the
(b) You did a great job picking up the and putting it in the
(c) I like how you are doing what I ask you to do.
(d) You are a good listener.
(e) Good job following instructions.

The statements that will be given the non-enthusiastic description group are as follows:

(a) You put the in the , you did.

(b) You picked up the and put it in the , yes, the in the

(c) You are doing exactly what I ask you to do.

(d) You are listening to me.

(e) You are following instructions. 
Appendix $\mathrm{C}$

Marble-in-the-Hole Game - Baseline

\begin{tabular}{|c|c|c|c|c|c|c|c|}
\hline \multicolumn{3}{|c|}{ Hole } & \multicolumn{3}{|c|}{ Hole } & \multicolumn{2}{|c|}{ Hole } \\
\hline 1. & Red & Green & 20. & Red & Green & 39. Red & Green \\
\hline 2. & Red & Green & 21. & Red & Green & Red & Green \\
\hline 3. & Red & Green & 22. & Red & Green & 41. Red & Green \\
\hline 4. & Red & Green & 23. & Red & Green & 42. Red & Green \\
\hline 5. & Red & Green & 24. & Red & Green & 43. Red & Green \\
\hline 6. & Red & Green & 25. & Red & Green & 44. Red & Green \\
\hline 7. & Red & Green & 26. & Red & Green & 45. Red & Green \\
\hline 8. & Red & Green & 27. & Red & Green & 46. Red & Green \\
\hline 9. & Red & Green & 28. & Red & Green & 47. Red & Green \\
\hline 10 & Red & Green & 29. & Red & Green & 48. Red & Green \\
\hline 11 & Red & Green & 30. & Red & Green & 49. Red & Green \\
\hline & Red & Green & 31. & Red & Green & 50. Red & Green \\
\hline & Red & Green & 32. & Red & Green & 51. Red & Green \\
\hline & Red & Green & 33. & Red & Green & 52. Red & Green \\
\hline & Red & Green & 34. & Red & Green & 53. Red & Green \\
\hline & Red & Green & 35. & Red & Green & 54. Red & Green \\
\hline & Red & Green & 36. & Red & Green & 55. Red & Green \\
\hline & Red & Green & 37. & Red & Green & 56. Red & Green \\
\hline & Red & Green & 38. & Red & Green & Red & Green \\
\hline
\end{tabular}




\section{Appendix D}

\section{Response statements for Marble-in-the-Hole Game.}

The statements that will be given to the enthusiastic, and non-enthusiastic praise groups are as follows:

(a) What a good boy you are for putting the marble in the red (green) hole.

(b) Very good, you put one in the red hole.

(c) I like it when you put it in the red hole.

(d) You're good at this game, you put another one in the red hole.

(e) Way to go, you put another marble in the red hole (Bernhardt \& Forehand, 1975).

The statements that will be given to the non-enthusiastic description group are as follows:

(a) You picked up the marble and put the marble in the red (green) hole.

(b) You put another one in the red hole.

(c) You put one in the red hole, that's the red hole.

(d) You picked up another marble and put it in the red hole.

(e) You put another marble in the red hole, the red hole. 


\section{Appendix E}

\section{Conner's Global Index}

Child Rated:

Rater:

Date:

\section{Instructions}

Read each item below carefully, and decide how much you think your student has been bothered by this problem in the past month. For each behavior described below, circle one number to indicate how much of a problem the behavior was for your student.

\begin{tabular}{|l|c|c|c|c|}
\hline & Not at all & Just a little & Pretty Much & Very much \\
\hline 1. Restless in the "squirmy" sense & 0 & 1 & 2 & 3 \\
\hline 2. Temper outbursts, unpredictable behavior & 0 & 1 & 2 & 3 \\
\hline 3. Distractibility or attention span a problem & 0 & 1 & 2 & 3 \\
\hline 4. Disturbs other children & 0 & 1 & 2 & 3 \\
\hline 5. Pouts and sulks & 0 & 1 & 2 & 3 \\
\hline 6. Mood changes quickly and drastically & 0 & 1 & 2 & 3 \\
\hline 7. Restless, always up and on the go & 0 & 1 & 2 & 3 \\
\hline 8. Excitable, impulsive & 0 & 1 & 2 & 3 \\
\hline 9. Fails to finish things & 0 & 1 & 2 & 3 \\
\hline 10. Easily frustrated in efforts & 0 & 1 & 2 & 3 \\
\hline
\end{tabular}


Appendix F

\section{Demographic Questionnaire}

Please complete the following information to the best of your ability.

Teacher's Name

Date

Child's Name

Child's Age

Child's Sex

Child's Race

Who are the child's caregivers?

Does the child come from a married, single parent, or blended family?

Are the child's caregivers employed? 


\section{Appendix G}

\section{Compliance Test}

\begin{tabular}{|c|c|c|c|c|c|c|c|}
\hline Command & Compliance & $\begin{array}{l}\text { Non- } \\
\text { compliance }\end{array}$ & $\begin{array}{l}\text { Non- } \\
\text { enthusiastic } \\
\text { Praise }\end{array}$ & $\begin{array}{l}\text { Enthusiastic } \\
\text { Praise }\end{array}$ & $\begin{array}{l}\text { Non-enthusiastic } \\
\text { Description }\end{array}$ & $\begin{array}{l}\text { Enthusiastic } \\
\text { Description }\end{array}$ & Nothing \\
\hline \multicolumn{8}{|l|}{ "[Name], put this dog in the box." } \\
\hline \multicolumn{8}{|l|}{ "[Name], put this car in the garage." } \\
\hline \multicolumn{8}{|l|}{ "[Name], put this block in the box." } \\
\hline \multicolumn{8}{|l|}{ "[Name], put this doll in the house." } \\
\hline \multicolumn{8}{|l|}{ "[Name], put this cow in the box." } \\
\hline \multicolumn{8}{|l|}{ "[Name], put this car in the garage." } \\
\hline \multicolumn{8}{|l|}{ "[Name], put this block in the box." } \\
\hline \multicolumn{8}{|l|}{ "[Name], put this doll in garage." } \\
\hline \multicolumn{8}{|l|}{ "[Name], put this horse in the box." } \\
\hline \multicolumn{8}{|l|}{ "[Name], put this car in the garage." } \\
\hline \multicolumn{8}{|l|}{ "[Name], put this block in the box." } \\
\hline \multicolumn{8}{|l|}{ "[Name], put this doll in the house." } \\
\hline \multicolumn{8}{|l|}{ "[Name], put this cow in the box." } \\
\hline \multicolumn{8}{|l|}{ "[Name], put this car in the house." } \\
\hline \multicolumn{8}{|l|}{ "[Name], put this block in the box." } \\
\hline \multicolumn{8}{|l|}{ "[Name $],$ put this doll in the house." } \\
\hline \multicolumn{8}{|l|}{ "[Name], put this dog in the box." } \\
\hline \multicolumn{8}{|l|}{ "[Name], put this car in the garage." } \\
\hline \multicolumn{8}{|l|}{ "[Name $],$ put this block in the box." } \\
\hline \multicolumn{8}{|l|}{ "[Name], put this doll in the house." } \\
\hline \multicolumn{8}{|l|}{ "[Name], put this horse in the box." } \\
\hline \multicolumn{8}{|l|}{ "[Name], put this car in the garage." } \\
\hline \multicolumn{8}{|l|}{ "[Name], put this block in the box." } \\
\hline \multicolumn{8}{|l|}{$\begin{array}{l}\text { "[Name }], \text { put this doll in the } \\
\text { garage." }\end{array}$} \\
\hline \multicolumn{8}{|l|}{ "[Name], put this pig in the box." } \\
\hline \multicolumn{8}{|l|}{ "[Name], put this car in the garage." } \\
\hline \multicolumn{8}{|l|}{ "[Name], put this block in the box." } \\
\hline \multicolumn{8}{|l|}{ "[Name], put this doll in the house." } \\
\hline \multicolumn{8}{|l|}{ "[Name], put this car in the garage." } \\
\hline "[Name], put this block in the box." & & & & & & & \\
\hline
\end{tabular}




\section{Appendix $\mathrm{H}$}

\section{Marble-in-the-Hole Game}

\begin{tabular}{|c|c|c|c|c|c|c|c|}
\hline \multirow{2}{*}{\multicolumn{3}{|c|}{$\begin{array}{l}\text { Least-preferred hole: } \quad \text { Red } \\
\text { Marble dropped in preferred hole }\end{array}$}} & \multicolumn{5}{|c|}{ Green } \\
\hline & & & \multirow{2}{*}{\begin{tabular}{|l}
$\begin{array}{l}\text { Non-enthusiastic } \\
\text { Praise }\end{array}$ \\
\end{tabular}} & \multirow[t]{2}{*}{ Enthusiastic Praise } & \multirow{2}{*}{$\begin{array}{l}\text { Non-enthusiastic } \\
\text { Description }\end{array}$} & \multirow[t]{2}{*}{ Enthusiastic Description } & \multirow[t]{2}{*}{ Nothing } \\
\hline 1. & Yes & No & & & & & \\
\hline 2. & Yes & No & & & & & \\
\hline 3. & Yes & No & & & & & \\
\hline 4. & Yes & No & & & & & \\
\hline 5. & Yes & No & & & & & \\
\hline 6. & Yes & No & & & & & \\
\hline 7. & Yes & No & & & & & \\
\hline 8. & Yes & No & & & & & \\
\hline 9. & Yes & No & & & & & \\
\hline 10. & Yes & No & & & & & \\
\hline 11. & Yes & No & & & & & \\
\hline 12. & Yes & No & & & & & \\
\hline 13. & Yes & No & & & & & \\
\hline 14. & Yes & No & & & & & \\
\hline 15. & Yes & No & & & & & \\
\hline 16. & Yes & No & & & & & \\
\hline 17. & Yes & No & & & & & \\
\hline 18. & Yes & No & & & & & \\
\hline 19. & Yes & No & & & & & \\
\hline 20. & Yes & No & & & & & \\
\hline 21. & Yes & No & & & & & \\
\hline 22. & Yes & No & & & & & \\
\hline 23. & Yes & No & & & & & \\
\hline 24. & Yes & No & & & & & \\
\hline 25. & Yes & No & & & & & \\
\hline 26. & Yes & No & & & & & \\
\hline 27. & Yes & No & & & & & \\
\hline 28. & Yes & No & & & & & \\
\hline 29. & Yes & No & & & & & \\
\hline 30. & Yes & No & & & & & \\
\hline
\end{tabular}




\section{Appendix I}

\begin{tabular}{|c|c|c|}
\hline & Typical Children & $\begin{array}{l}\text { Children with Disruptive } \\
\text { Behaviors }\end{array}$ \\
\hline Non-Enthusiastic Description & $\begin{array}{l}\text { Compliance Test } \\
\text { Marble-in-the-Hole Game }\end{array}$ & $\begin{array}{l}\text { Compliance Test } \\
\text { Marble-in-the-Hole Game }\end{array}$ \\
\hline Non-Enthusiastic Praise & $\begin{array}{l}\text { Compliance Test } \\
\text { Marble-in-the-Hole Game }\end{array}$ & $\begin{array}{l}\text { Compliance Test } \\
\text { Marble-in-the-Hole Game }\end{array}$ \\
\hline Enthusiastic Praise & $\begin{array}{l}\text { Compliance Test } \\
\text { Marble-in-the-Hole Game }\end{array}$ & $\begin{array}{l}\text { Compliance Test } \\
\text { Marble-in-the-Hole Game }\end{array}$ \\
\hline
\end{tabular}


Table 1

Means and Standard Deviations for the Compliance Test

\begin{tabular}{lllll}
\hline & & \multicolumn{3}{c}{ Condition } \\
\cline { 3 - 5 } Group & $\underline{\mathrm{n}}$ & $\mathrm{NEP}$ & EP & NED \\
\hline
\end{tabular}

Disruptive 15

$\begin{array}{llll}\underline{\mathrm{M}} & 65.34 & 63.33 & 72.89 \\ \underline{\mathrm{SD}} & 27.16 & 32.81 & 28.00\end{array}$

Typical 15

$\begin{array}{llll}\underline{\mathrm{M}} & 78.22 & 79.78 & 88.44 \\ \underline{\mathrm{SD}} & 24.59 & 20.95 & 8.44\end{array}$

Combined $\quad 30$

$\begin{array}{llll}\underline{\mathrm{M}} & 71.78^{*} & 71.56 & 80.67^{*} \\ \underline{\mathrm{SD}} & 26.29 & 28.31 & 21.80\end{array}$

Note. $\mathrm{NEP}=$ non-enthusiastic praise $; \mathrm{EP}=$ enthusiastic praise $; \mathrm{NED}=$ non-enthusiastic description.

*Differ significantly $(\underline{p}<.05)$. 
Table 2

Missing Data Points in the Marble-in-the-Hole Game

\begin{tabular}{|c|c|c|c|c|c|c|}
\hline \multirow[b]{2}{*}{ Condition } & \multicolumn{2}{|c|}{ Disruptive } & \multicolumn{2}{|c|}{ Typical } & \multicolumn{2}{|c|}{ Combined } \\
\hline & Off-task & Same hole & Off-task & Same hole & Off-task & Same hole \\
\hline NEP & 1 & 1 & 0 & 0 & 1 & 1 \\
\hline EP & 2 & 2 & 0 & 1 & 2 & 3 \\
\hline NED & 0 & 1 & 0 & 2 & 0 & 3 \\
\hline
\end{tabular}


Table 3

Means and Standard Deviations for the Marble-in-the-Hole Game

\begin{tabular}{lllll}
\hline & & \multicolumn{3}{c}{ Condition } \\
\cline { 3 - 5 } Group & $\underline{\mathrm{n}}$ & $\mathrm{NEP}$ & EP & NED \\
\hline
\end{tabular}

Disruptive 15

$\begin{array}{llll}\underline{\mathrm{M}} & 67.17(65.33) & 63.75(62.35) & 53.96(50.89) \\ \underline{\mathrm{SD}} & 24.48(27.64) & 25.58(31.52) & 29.31(33.23)\end{array}$

Typical 15

$\begin{array}{llll}\underline{\mathrm{M}} & 58.04(58.53) & 80.97(79.84) & 48.96(48.65) \\ \underline{\mathrm{SD}} & 32.84(31.98) & 22.19(23.52) & 34.31(36.76)\end{array}$

Combined $\quad 30$

$\begin{array}{llll}\underline{\mathrm{M}} & 62.61(61.49) & 72.36^{*}(72.23) & 51.31 *(49.62) \\ \underline{\mathrm{SD}} & 28.84(29.78) & 25.10(28.07) & 31.32(34.50)\end{array}$

Note. $\mathrm{NEP}=$ non-enthusiastic praise; $\mathrm{EP}=$ enthusiastic praise $; \mathrm{NED}=$ non-enthusiastic description.

Values enclosed in parentheses represent data obtained with missing data points not replaced in analysis.

*Differ significantly $(\underline{p}<.05)$. 